\title{
Discovery of Double-Stranded Genomic DNA in Circulating Exosomes
}

\author{
Raghu Kalluri and Valerie S. LeBleu \\ Department of Cancer Biology, Metastasis Research Center, University of Texas MD Anderson Cancer \\ Center, Houston, Texas 77005 \\ Correspondence: rkalluri@mdanderson.org; vlebleu@mdanderson.org
}

\begin{abstract}
It is becoming increasingly clear that small vesicles released from cells (extracellular vesicles [EVs]) represent a heterogeneous population implicated in cell-to-cell communication. The classifications and nomenclature of EVs are evolving as enrichment strategies and specific characteristics are being unraveled. At present, physical properties of EVs - namely, size, shape, and density - are often used to identify subpopulations of EVs. A distinct group of EVs, termed exosomes, largely defined by their small size $(\sim 40-150 \mathrm{~nm})$ and proposed subcellular origin, has been extensively studied in several aspects of cancer biology. Exosomes are implicated in modulating behavior of cancer cells as well as the immune and angiogenic responses in tumors, possibly contributing to cancer progression locally and systemically. Most intriguingly, the nucleic acid content of exosomes has been proposed to play a role in oncogenic transformation and transfer of cancer-specific genome to promote cancer pathogenesis. Here, we specifically focus on the discovery of exosomal DNA, studies related to the origin of genomic DNA in exosomes, and its utility in cancer diagnosis and disease monitoring.
\end{abstract}

Exosomes are extracellular vesicles (EVs) released via fusion of multivesicular bodies with the plasma membrane of cells. The content of the multivesicular bodies (intraluminal vesicles [ILVs]) is released in the form of exosomes in the extracellular space (Colombo et al. 2014; Kalluri 2016). This propositioned biogenesis is in contrast with that of "ectosomes," which emerge from the direct budding of the plasma membrane, giving rise to EVs of similar or greater size range when compared with exosomes (Fig. 1; Antonyak and Cerione 2015; Cocucci and Meldolesi 2015). Despite novel biology unraveling these processes, the exact molecular mechanism of exosome and ectosome formation is unknown. It remains challenging to definitively distinguish between exosomes and ectosomes, in particular when they share similar physical characteristics (size, shape, and density) and present with markers that can overlap between the two subpopulations. There are to date no definitive markers or processes to strictly enrich exosomes versus ectosomes, although proteins involved in their biogenesis are being rapidly unraveled (Colombo et al. 2014; Edgar 2016; Tkach and Thery 2016). The biogenesis of exosomes and ectosomes may play a role in defining their respective contents. Exosomes are implicated in intercellular exchange of macromolecules involving proteins, metabolites, lipids, mRNA, miRNA, lncRNA, viral RNA, mitochondrial, and chromosomal DNA (Kalluri 2016). Collectively, exosomes may present with a heterogeneous mixture of all cellular componenets (Fig. 1), raising an intriguing notion that exosomes may resemble "primordial"-like vesicles (Sinkovics 2015; Kalluri 2016). The evidence for the functional impact of cellular exchange of exosomal content, such as signaling molecules, messenger RNA (mRNA), and microRNA (miRNA), implicates exosomes in widespread multiorgan communication. The functional outcome of such exchange may not be limited to neoplastic events and tumor growth but also involve embryonic/organ development and non-cancer-associated pathologies (Colombo et al. 2014; Edgar 2016; McGough and Vincent 2016; Tkach and Thery 2016).

Most results related to cell-cell communication mediated by exosomes, although intriguing, have largely been collected from experiments performed employing cell culture system or employing experimental designs wherein animals are given bolus administration of large quantities of exogenously prepared exosomes from cultured cells. It is critical to note that the physiological function of exosomes remains largely unknown. Several factors have been implicated in the release of exosomes, and the loss of the tumor suppressor-activated pathway 6 (TSAP6) gene in mice results in abnormal transferrin receptor down-regulation and reticulocyte maturation (Lespagnol et al. 2008) - processes that were first described in exosome biogenesis (Colombo et al. 2014; Edgar 2016). Interestingly, this process was linked to the DNA damage-induced TP53 pathway associated with exosome secretion (Lespagnol et al. 2008). It remains unknown whether such exosome secretion pathways are similar in all cell types. Emerging studies suggest distinct molecular mechanisms for exosome biogenesis, independent of the traditionally discussed endosomal sorting complexes required for transport (ESCRT)-dependent process (Stuffers et al. 2009). (C) 2016 Kalluri and LeBleu. This article is distributed under the terms of the Creative Commons Attribution-NonCommercial License, which permits
reuse and redistribution, except for commercial purposes, provided that the original author and source are credited. 


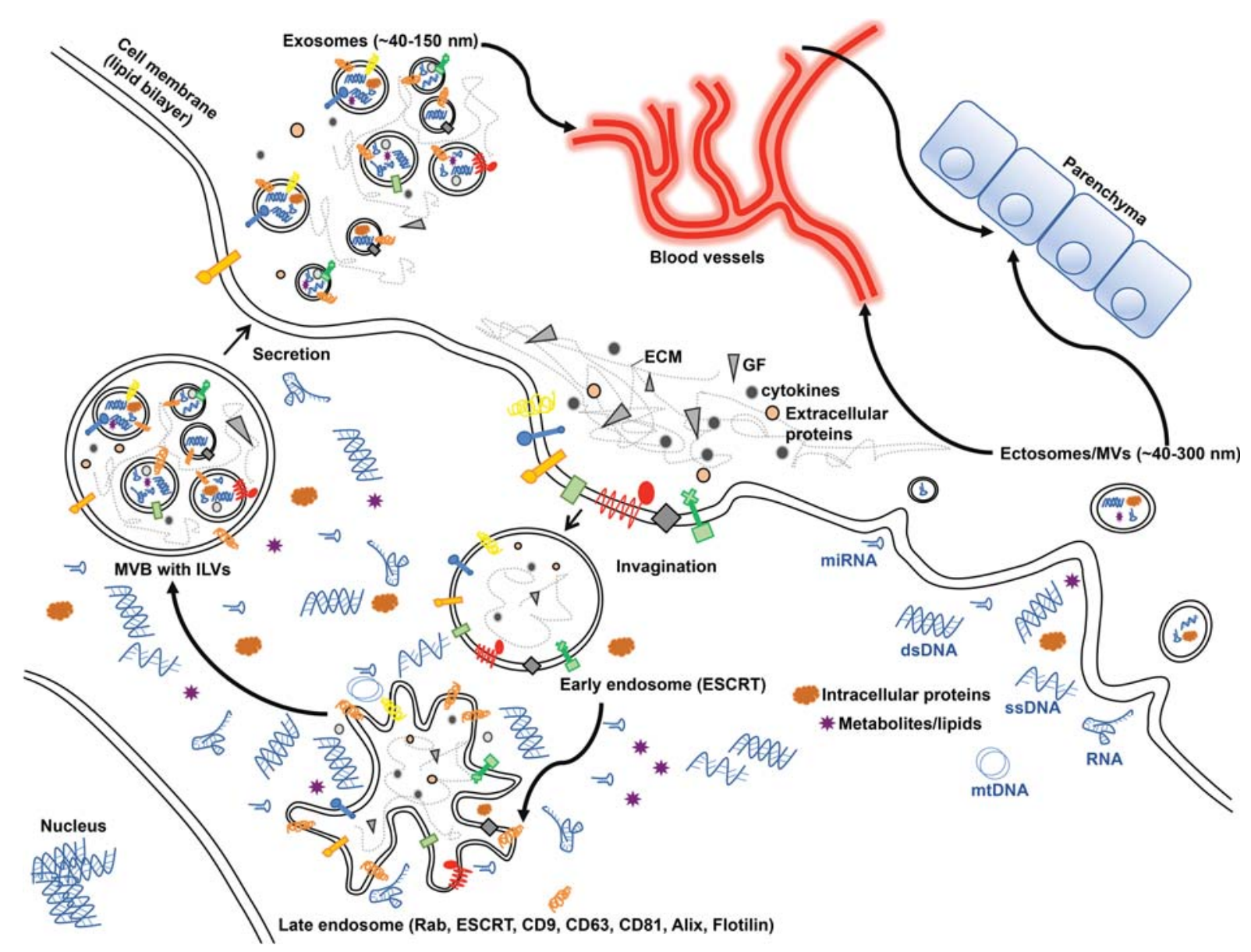

Figure 1. Invagination of the cell plasma membrane leads to the formation of intercellular vesicles encapsulating extracellular components (extracellular matrix [ECM], extracellular proteins, cytokines, and growth factors [GFs]). The intracellular vesicles mature into the early and late endosomes, implicating the endosomal sorting complexes required for transport (ESCRT) machinery and Rab proteins. Proteins (CD9, CD63, CD81, Alix, Flotilin) that decorate the late endosomes are often used as exosome markers following their secretion. The formation of the multivesicular body (MVB) containing the intraluminal vesicles (ILVs) follows a secondary invagination of the late endosome membranes, trapping within newly forming ILVs components of the cytosol (metabolites, intracellular proteins, nucleic acids). Following fusion of the MVs with the plasma membrane, the ILVs are released and referred to as exosomes. The surface proteins on the released exosomes are conformed similarly to their presentation on the plasma membrane. The exosomes enter the circulation or surrounding parenchyma. Ectosomes or microvesicles (MVs), in contrast, emerge from the budding of the plasma membrane and are often larger in size when compared to exosomes. miRNA, microRNA; dsDNA, double-stranded DNA; ssDNA, single-stranded DNA; mtDNA, mitochondrial DNA.

In cancer, the biology and function of exosomes is still largely unknown, and some suggestive evidence today points to their role in promoting cancer (Kahlert and Kalluri 2013; Yu et al. 2015; Kalluri 2016). Cancer cellderived exosomes may elicit phenotypic and molecular responses in recipient cells that result in the activation of signaling pathways that may promote cancer cell proliferation, survival, invasion, and resistance to therapy ( $\mathrm{Yu}$ et al. 2015). Tumor-derived exosomes may also remodel the tumor microenvironment to promote tumor angiogenesis and impair the immune control of tumor growth (Kahlert and Kalluri 2013). The content of cancer cellderived exosomes may reflect the content of their cell of origin, perpetuating potential transfer of specific oncogenic components to recipient cells (Fujita et al. 2016; Choi et al. 2017). Interestingly, exosomes may also serve as a modulator of cancer cell heterogeneity, possibly im- pacting the populational equilibrium of diffuse B-cell lymphoma (Koch et al. 2014). Although these effects are largely attributed to signaling molecules and epigenetic regulators delivered into the recipient cells by exosomes, another intriguing mode of communication by exosomes entails the DNA present in them. Exosomes were reported to contain mitochondrial DNA (from culture supernatant of myoblasts [Guescini et al. 2010]) and chromosomal DNA (vide infra). Chromosomal DNA in exosomes was noted in cell culture supernatant as well as in human and mouse biological fluids, including blood, seminal fluid, and urine. Interestingly, the encapsulation of DNA within exosomes may confer enhanced stability to DNA when outside the cell (Jin et al. 2016). These discoveries have spurred a specific interest in exosomes DNA for use as liquid biopsies to facilitate the diagnosis and monitoring of cancer patients (Speicher and Pantel 
2014; Wan et al. 2017; Yi et al. 2017). The exosomal DNA in the blood offers yet another level of complexity in the study of circulating DNA in cancer (Thierry et al. 2016) but also perhaps novel means to isolate cancer specific DNA, by possibly enriching for circulating exosomes derived from cancer cells (Kalluri 2016).

\section{IDENTIFICATION OF DNA IN THE EXOSOMES}

Using whole-genome sequencing, Kahlert et al. (2014) provided definitive identification of large fragments of double-stranded genomic DNA (cumulatively encompassing all chromosomes) in the circulating exosomes from patients with pancreatic cancer and also in exosomes derived from cancer cells. Several groups have also identified double-stranded DNA fragments in the exosomes ranging from $100 \mathrm{~b}$ to $17 \mathrm{~kb}$ in size (Cai et al. 2013; Kahlert et al. 2014; Lee et al. 2014; Thakur et al. 2014). Cai et al. (2013) reported the detection of chromosomal and mitochondrial DNA in exosomes derived from healthy donor human plasma and culture supernatant of human primary vascular smooth muscle cells, HEK293 cells (human embryonic kidney cells) and K562 cells (human immortalized myelogenous leukemia cells) (Cai et al. 2013). In their studies, DNase treatment supported that the long fragments of doublestranded DNA were predominantly found within the exosomes rather than outside. They further showed that the exosome's DNA, upon transfer to the recipient cells, localizes to the nucleus, recruits nuclear factor $\kappa \mathrm{B}(\mathrm{NF}-$ $\kappa \mathrm{B})$, and is transcribed. Further, exosome-derived DNA containing the BCR/ABL hybrid gene (from K562 cell supernatant) could be detected in normal recipient human neutrophils (Cai et al. 2013). Their results support the notion of functional horizontal transfer of DNA via exosomes (Cai et al. 2013, 2016). The detection of gene fusion in exosome's DNA sets the stage for further analyses of driver mutations in several cancer types.

\section{DETECTION OF DNA MUTATIONS IN EXOSOMES}

In the supernatants of pancreatic cancer cells and serum from pancreatic cancer patients, large fragments of double-stranded DNA were noted in exosomes, and Sanger sequencing analyses of polymerase chain reaction (PCR) amplicons revealed the presence of KRAS and TP53 mutations (Kahlert et al. 2014). The double-stranded DNA in exosomes collected from prostate cancer cell supernatant also revealed mutations characteristic of the cell of origin (Lazaro-Ibanez et al. 2014), and doublestranded DNA was also identified in the plasma of prostate cancer patients (Lazaro-Ibanez et al. 2014) as well as in the seminal fluid of donors (Ronquist et al. 2012). The diagnostic value of exosome's DNA in liquid biopsies, including but not limited to blood, urine, and seminal fluid, remains to be determined because of the challenges associated with detection sensitivity and signal-to-noise ratio owing to fragments of DNA from cancer cells (mutation) mixed with DNA from normal cells (no mutation). Nonetheless, detection of actionable mutations (in NOTCH1 and BRCA2) in exosome's DNA from pancreatic cancer patients has been reported (San Lucas et al. 2016). The most common mutations in pancreatic cancer patients (KRAS and TP53) are readily detected in circulating exosomes DNA (Allenson et al. 2017; Yang et al. 2017). These studies, however, provide caution because detection of KRAS mutation from an exosome's DNA in healthy individuals confounds the diagnostic utility. The exosome's DNA in cancer may indeed represent a new treasure trove for monitoring changes in the mutational landscape (e.g., in response to therapy); however, this may only be feasible upon enrichment of cancer cellderived exosomes from the blood (Kalluri 2016).

\section{BIOLOGICAL FUNCTION OF DNA IN THE EXOSOMES}

The exact nature and relative abundance of the different species of DNA inside and outside of exosomes from cell culture supernatants and biological fluids is being actively investigated. It is likely that distinct types (singlestranded, double-stranded, mitochondrial; Fig. 2) and integrity of the exosome's DNA (fragment length, chromatin bound) are likely possible in the distinct type of exosomes based on their cell of origin. It is also plausible that the mechanisms enabling packaging of DNA within exosomes are cell type-specific and dynamically regulated. Analyses of exosomes from the supernatant of various cancer cell lines and non-cancer-associated fibroblast lines revealed exosomes DNA was more abundant in cancer cell-derived exosomes, and that double-stranded DNA was predominantly found within the exosomes (Kahlert et al. 2014; Thakur et al. 2014). DNase treatment of exosomes from cultured cell supernatants revealed that double-stranded DNA, rather than single-stranded DNA or RNA, was predominantly found inside exosomes, albeit DNA is also found outside exosomes (Kahlert et al. 2014; Thakur et al. 2014). This is in contrast with the reported single-stranded DNA in exosomes from the supernatant of medulloblastoma tumor cells (Balaj et al. 2011). Whole-genome sequence analyses revealed the entire coverage of the genome in exosomes and that there did not seem to be a notable bias for specific regions (Kahlert et al. 2014; Lee et al. 2014; Thakur et al. 2014). Using exosomes containing H-ras DNA sequence, derived from the culture supernatant of RAS-3 cells (tumorigenic c-H-ras transformed rat intestinal epithelial cells), the recipient RAT-1 cells (immortalized rat fibroblasts) showed transient H-ras DNA for up to $30 \mathrm{~d}$ following exposure to exosomes (Lee et al. 2014). Although this uptake did not transform RAT-1 cells, RAS-3-derived exosomes stimulated their proliferation (Lee et al. 2014).

BRCA1-KO human fibroblasts could be transformed into malignant cells when exposed to circulating exosomes from patients with breast, colorectal, pancreatic, and other 


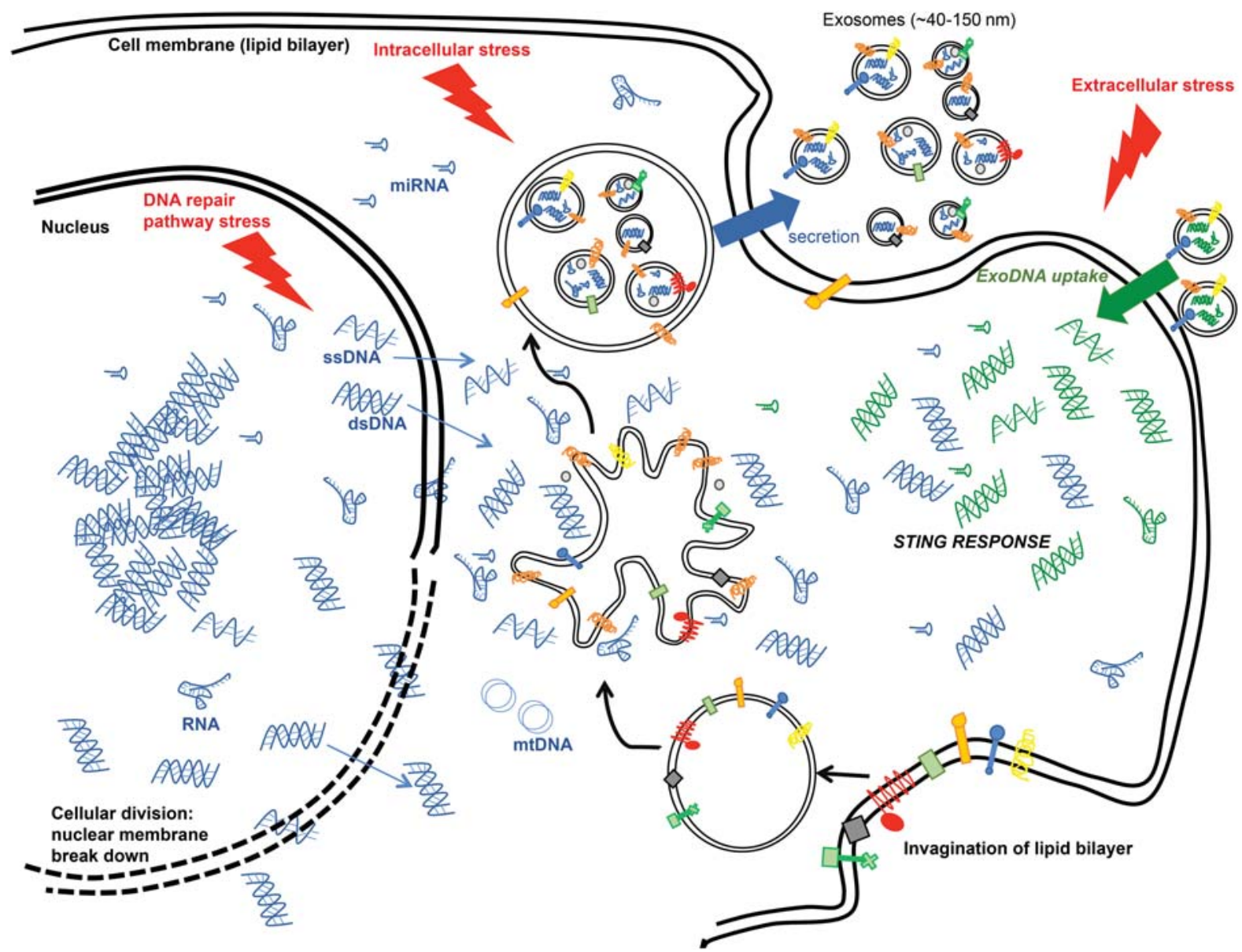

Figure 2. During the formation of intraluminal vesicles that will subsequently be released as exosomes, nucleic acids in the cytosol are encapsulated. These include messenger RNA (mRNA), microRNA (miRNA), mitochondrial DNA (mtDNA), and single-stranded and double-stranded chromosomal DNA (ssDNA and dsDNA, respectively). Increased cellular stress (extracellular stress, intracellular stress, and DNA repair pathway stress) may contribute to the increase in cytosolic nucleic acids that are shuttled into intraluminal vesicles (ILVs). Breakdown of the nuclear membrane during cellular division may also expose extraneous DNA to cytosolic compartments that would facilitate DNA uptake into ILVs. The increased content of cytosolic DNA, possibly via uptake of exosomal DNA, may elicit the stimulator of interferon genes (STING) pathway and stimulate an immune response.

cancer types (Hamam et al. 2016). Interestingly, studies using epidermal growth factor receptor (EGFR)-driven cancer cell lines subjected to EGFR kinase inhibitors yield an increase in the release of exosomes containing DNA (Montermini et al. 2015). Collectively these studies indicate that exosomal DNA cargo can be different but predominantly present as large fragments of doublestranded DNA. Moreover, DNA packaging may be influenced by exogenous agents acting on the cell of origin, yet with all regions of the genome appearing to be contained within a given pool of exosomes (billions). Further, the influence of exosomal DNA on the recipient cells may differ based on pre-existing genomic and microenvironmental stressors. The impact of an exosome's DNA may extend beyond cell-cell communications. Recent studies revealed that breast cancer cell-derived exosomal DNA, following treatment of the cancer cells with topoisomerase I inhibitor, may activate the stimulator of interferon genes (STING) pathway in the recipient dendritic cells (Fig. 2; Paludan and Bowie 2013; Kitai et al. 2017). Whether these events are rate-limiting for antitumor immunity remains to be determined, but it certainly opens a new means to modulate tumor immunity via exosomal DNA.

\section{FUTURE DIRECTIONS}

Among the fascinating, yet largely unanswered questions surrounding exosomal DNA are the mechanisms associated with chromosomal DNA packaging within ILVs, which eventually give rise to exosomes when released into the extracellular space. Because the biogenesis of ILVs could include the sampling of the cytosol, cytosolic chromosomal DNA likely can get encapsulated within the exosomes (Fig. 2). Cytosolic DNA accumulation in cancer cells may reflect their deregulated DNA repair pathways (Shen et al. 2015; Ho et al. 2016), and this could explain the higher abundance of exosomal DNA in cancer cells when compared with normal cells. 
Alternatively, the different expression levels of cytosolic nucleases in distinct cell types, leading to enhanced cytosolic DNA content, could also account for different amounts of DNA within ILVs. Whether a correlation exists between cytosolic DNA content and abundance of exosomal DNA remains to be elucidated. Intriguingly, there may be a link between nuclear envelope breakdown in proliferating cells and vesicular packaging of aborted DNA replication forks (Fig. 2), although this hypothesis remains to be tested. The mechanism underlying the transfer of an exosome's DNA to its recipient cells is also largely unknown, although exosomal Connexin 43 (GJA1 or Cx43) may enable docking and fusion of exosomes with the plasma membrane of Cx43 expressing recipient cells (Soares et al. 2015). The green fluorescent protein (GFP)-expressing plasmid incorporated into the $\mathrm{Cx} 43^{+}$exosomes was more efficiently transcribed and translated when $\mathrm{Cx} 43$ was present on both exosomes and recipient cell surfaces (Soares et al. 2015). Interestingly, predicted DNA and RNA-binding motifs on Cx43 could suggest a role for Cx43 in exosome-mediated transfer of nucleic acids (Varela-Eirin et al. 2017).

In conclusion, many research groups validated the fascinating discovery that exosomes contain genomic double-stranded DNA. In the next decade, we will gain more knowledge with respect to the mechanism of how DNA enters the exosomes and how exosomal DNA can aid in diagnosis and therapy of cancer.

\section{ACKNOWLEDGMENTS}

The work in the laboratory of R.K. is supported by the Cancer Prevention and Research Institute of Texas. The V.S.L. laboratory is supported by the University of Texas MD Anderson Cancer Center (UT MDACC) Khalifa Bin Zayed Al Nahyan Foundation.

\section{REFERENCES}

Allenson K, Castillo J, San Lucas FA, Scelo G, Kim DU, Bernard V, Davis G, Kumar T, Katz M, Overman MJ, et al. 2017. High prevalence of mutant KRAS in circulating exosomederived DNA from early stage pancreatic cancer patients. Ann Oncol. doi: 10.1093/annonc/mdx004.

Antonyak MA, Cerione RA. 2015. Emerging picture of the distinct traits and functions of microvesicles and exosomes. Proc Natl Acad Sci 112: 3589-3590.

Balaj L, Lessard R, Dai L, Cho YJ, Pomeroy SL, Breakefield XO, Skog J. 2011. Tumour microvesicles contain retrotransposon elements and amplified oncogene sequences. Nat Commun 2: 180.

Cai J, Han Y, Ren H, Chen C, He D, Zhou L, Eisner GM, Asico LD, Jose PA, Zeng C. 2013. Extracellular vesicle-mediated transfer of donor genomic DNA to recipient cells is a novel mechanism for genetic influence between cells. J Mol Cell Biol 5: 227-238.

Cai J, Wu G, Jose PA, Zeng C. 2016. Functional transferred DNA within extracellular vesicles. Exp Cell Res 349: 179183.

Choi D, Lee TH, Spinelli C, Chennakrishnaiah S, D'Asti E, Rak J. 2017. Extracellular vesicle communication pathways as regulatory targets of oncogenic transformation. Semin Cell Dev Biol. doi: 10.1016/j.semcdb.2017.01.003.
Cocucci E, Meldolesi J. 2015. Ectosomes and exosomes: Shedding the confusion between extracellular vesicles. Trends Cell Biol 25: 364-372.

Colombo M, Raposo G, Thery C. 2014. Biogenesis, secretion, and intercellular interactions of exosomes and other extracellular vesicles. Annu Rev Cell Dev Biol 30: 255-289.

Edgar JR. 2016. Q\&A: What are exosomes, exactly? BMC Biol 14: 46.

Fujita Y, Yoshioka Y, Ochiya T. 2016. Extracellular vesicle transfer of cancer pathogenic components. Cancer Sci 107: 385-390.

Guescini M, Guidolin D, Vallorani L, Casadei L, Gioacchini AM, Tibollo P, Battistelli M, Falcieri E, Battistin L, Agnati LF, et al. 2010. C2C12 myoblasts release micro-vesicles containing mtDNA and proteins involved in signal transduction. Exp Cell Res 316: 1977-1984.

Hamam D, Abdouh M, Gao ZH, Arena V, Arena M, Arena GO. 2016. Transfer of malignant trait to BRCA1 deficient human fibroblasts following exposure to serum of cancer patients. $J$ Exp Clin Cancer Res 35: 80.

Ho SS, Zhang WY, Tan NY, Khatoo M, Suter MA, Tripathi S, Cheung FS, Lim WK, Tan PH, Ngeow J, et al. 2016. The DNA structure-specific endonuclease MUS81 mediates DNA sensor STING-dependent host rejection of prostate cancer cells. Immunity 44: 1177-1189.

Jin Y, Chen K, Wang Z, Wang Y, Liu J, Lin L, Shao Y, Gao L, Yin $\mathrm{H}$, Cui C, et al. 2016. DNA in serum extracellular vesicles is stable under different storage conditions. BMC Cancer 16: 753.

Kahlert C, Kalluri R. 2013. Exosomes in tumor microenvironment influence cancer progression and metastasis. J Mol Med (Berl) 91: 431-437.

Kahlert C, Melo SA, Protopopov A, Tang J, Seth S, Koch M, Zhang J, Weitz J, Chin L, Futreal A, et al. 2014. Identification of double-stranded genomic DNA spanning all chromosomes with mutated KRAS and p53 DNA in the serum exosomes of patients with pancreatic cancer. J Biol Chem 289: $3869-$ 3875.

Kalluri R. 2016. The biology and function of exosomes in cancer. J Clin Invest 126: $1208-1215$.

Kitai Y, Kawasaki T, Sueyoshi T, Kobiyama K, Ishii KJ, Zou J, Akira S, Matsuda T, Kawai T. 2017. DNA-containing exosomes derived from cancer cells treated with topotecan activate a STING-dependent pathway and reinforce antitumor immunity. J Immunol 198: 1649-1659.

Koch R, Demant M, Aung T, Diering N, Cicholas A, Chapuy B, Wenzel D, Lahmann M, Guntsch A, Kiecke C, et al. 2014. Populational equilibrium through exosome-mediated Wnt signaling in tumor progression of diffuse large B-cell lymphoma. Blood 123: 2189-2198.

Lazaro-Ibanez E, Sanz-Garcia A, Visakorpi T, Escobedo-Lucea C, Siljander P, Ayuso-Sacido A, Yliperttula M. 2014. Different gDNA content in the subpopulations of prostate cancer extracellular vesicles: Apoptotic bodies, microvesicles, and exosomes. Prostate 74: 1379-1390.

Lee TH, Chennakrishnaiah S, Audemard E, Montermini L, Meehan B, Rak J. 2014. Oncogenic ras-driven cancer cell vesiculation leads to emission of double-stranded DNA capable of interacting with target cells. Biochem Biophys Res Commun 451: 295-301.

Lespagnol A, Duflaut D, Beekman C, Blanc L, Fiucci G, Marine JC, Vidal M, Amson R, Telerman A. 2008. Exosome secretion, including the DNA damage-induced p53-dependent secretory pathway, is severely compromised in TSAP6/ Steap3-null mice. Cell Death Differ 15: 1723-1733.

McGough IJ, Vincent JP. 2016. Exosomes in developmental signalling. Development 143: 2482-2493.

Montermini L, Meehan B, Garnier D, Lee WJ, Lee TH, Guha A, Al-Nedawi K, Rak J. 2015. Inhibition of oncogenic epidermal growth factor receptor kinase triggers release of exosome-like extracellular vesicles and impacts their phosphoprotein and DNA content. J Biol Chem 290: 24534-24546.

Paludan SR, Bowie AG. 2013. Immune sensing of DNA. Immunity 38: $870-880$. 
Ronquist GK, Larsson A, Stavreus-Evers A, Ronquist G. 2012. Prostasomes are heterogeneous regarding size and appearance but affiliated to one DNA-containing exosome family. Prostate 72: $1736-1745$.

San Lucas FA, Allenson K, Bernard V, Castillo J, Kim DU, Ellis K, Ehli EA, Davies GE, Petersen JL, Li D, et al. 2016. Minimally invasive genomic and transcriptomic profiling of visceral cancers by next-generation sequencing of circulating exosomes. Ann Oncol 27: 635-641.

Shen YJ, Le Bert N, Chitre AA, Koo CX, Nga XH, Ho SS, Khatoo M, Tan NY, Ishii KJ, Gasser S. 2015. Genome-derived cytosolic DNA mediates type I interferon-dependent rejection of B cell lymphoma cells. Cell Rep 11: 460-473.

Sinkovics JG. 2015. The cell survival pathways of the primordial RNA-DNA complex remain conserved in the extant genomes and may function as proto-oncogenes. Eur J Microbiol Immunol (Bp) 5: 25-43.

Soares AR, Martins-Marques T, Ribeiro-Rodrigues T, Ferreira JV, Catarino S, Pinho MJ, Zuzarte M, Anjo SI, Manadas B, Sluijter JP, et al. 2015. Corrigendum: Gap junctional protein $\mathrm{Cx} 43$ is involved in the communication between extracellular vesicles and mammalian cells. Sci Rep 5: 14888.

Speicher MR, Pantel K. 2014. Tumor signatures in the blood. Nat Biotechnol 32: 441-443.

Stuffers S, Sem Wegner C, Stenmark H, Brech A. 2009. Multivesicular endosome biogenesis in the absence of ESCRTs. Traffic 10: 925-937.

Thakur BK, Zhang H, Becker A, Matei I, Huang Y, Costa-Silva B, Zheng Y, Hoshino A, Brazier H, Xiang J, et al. 2014.
Double-stranded DNA in exosomes: A novel biomarker in cancer detection. Cell Res 24: 766-769.

Thierry AR, El Messaoudi S, Gahan PB, Anker P, Stroun M. 2016. Origins, structures, and functions of circulating DNA in oncology. Cancer Metastasis Rev 35: 347-376.

Tkach M, Thery C. 2016. Communication by extracellular vesicles: Where we are and where we need to go. Cell 164: $1226-1232$.

Varela-Eirin M, Varela-Vazquez A, Rodriguez-Candela Mateos M, Vila-Sanjurjo A, Fonseca E, Mascarenas JL, Eugenio Vazquez M, Mayan MD. 2017. Recruitment of RNA molecules by connexin RNA-binding motifs: Implication in RNA and DNA transport through microvesicles and exosomes. Biochim Biophys Acta 1864: 728-736.

Wan JC, Massie C, Garcia-Corbacho J, Mouliere F, Brenton JD, Caldas C, Pacey S, Baird R, Rosenfeld N. 2017. Liquid biopsies come of age: Towards implementation of circulating tumour DNA. Nat Rev Cancer 17: 223-238.

Yang S, Che SP, Kurywchak P, Tavormina JL, Gansmo LB, Correa de Sampaio P, Tachezy M, Bockhorn M, Gebauer F, Haltom AR, et al. 2017. Detection of mutant KRAS and TP53 DNA in circulating exosomes from healthy individuals and patients with pancreatic cancer. Cancer Biol Ther 18: 158-165.

Yi X, Ma J, Guan Y, Chen R, Yang L, Xia X. 2017. The feasibility of using mutation detection in ctDNA to assess tumor dynamics. Int J Cancer. doi: 10.1002/ijc.30620.

Yu S, Cao H, Shen B, Feng J. 2015. Tumor-derived exosomes in cancer progression and treatment failure. Oncotarget 6: 37151-37168. 


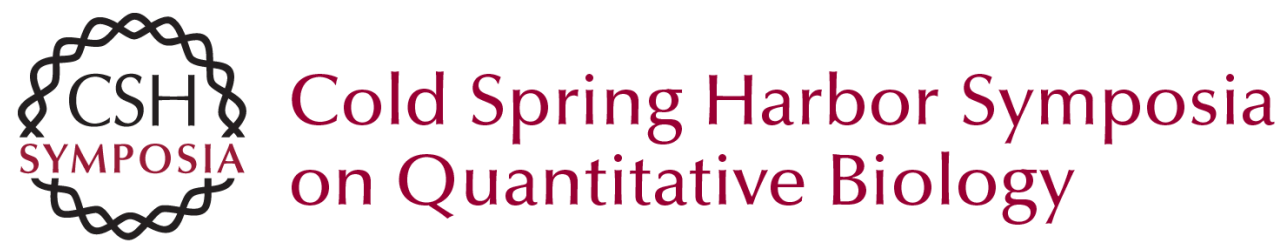

\section{Discovery of Double-Stranded Genomic DNA in Circulating Exosomes}

Raghu Kalluri and Valerie S. LeBleu

Cold Spring Harb Symp Quant Biol 2016 81: 275-280 originally published online April 19, 2017 Access the most recent version at doi:10.1101/sqb.2016.81.030932

References This article cites 40 articles, 6 of which can be accessed free at: http://symposium.cshlp.org/content/81/275.full.html\#ref-list-1

Creative This article is distributed under the terms of the

Commons http://creativecommons.org/licenses/by-nc/4.0/, which permits reuse and License redistribution, except for commercial purposes, provided that the original author and source are credited.

Email Alerting Receive free email alerts when new articles cite this article - sign up in Service the box at the top right corner of the article or click here. 